observation that the rate of spontaneous abortion increases with the duration and severity of maternal diabetes. ${ }^{8}$

Because of the regularity of the menstrual histories of our patients and the association between delay and malformation we find a delay in ovulation of up to more than three weeks inconceivable as an explanation of the observed growth delay. We hope to measure basal body temperatures in patients, which should provide us with final proof. We have seen only a normal rate of growth after the first determination of crown-rump length in the first trimester. Thus the delay must be introduced somewhere between ovulation and the first ultrasound examination in weeks 7-14. For comparison, embryologic considerations have shown that the factor causing the malformation must be active before the seventh week. ${ }^{9}$

There is some indirect evidence that good regulation of diabetes reduces the number of malformed fetuses ${ }^{1011}$ and of appreciably delayed fetuses. ${ }^{5}$ We hope to obtain further substantiation by measuring $\mathrm{HbA} /{ }_{1 \mathrm{c}}{ }^{10}$ Perhaps, therefore, the same mechanism that is responsible for the early delay of up to several weeks in fetal growth and the biological clock sometimes also induces abnormal embryogenesis (or even causes death of the embryo). The biochemical nature of this mechanism is unknown.

We have shown that considerable early growth delay, especially in White's classes D and F, entails a severe risk of fetal malformation. Paediatric follow-up might even show an overrepresentation of additional minor malformations or impaired development in this group. If a larger series and studies from other centres confirm our findings these must influence counselling to the prospective and early pregnant diabetic.
Requests for reprints should be sent to Dr Jan Fog Pedersen, Ultrasound Laboratory, Glostrup University Hospital, DK 2600 Glostrup, Denmark.

\section{References}

${ }^{1}$ Pedersen LM, Tygstrup I, Pedersen J. Congenital malformation in newborn infants of diabetic women. Lancet 1964; ; :1124-6.

${ }^{2}$ Kucera J. Rate and type of congenital anomalies among offspring of diabetic women. $\mathcal{F}$ Reprod Med 1971; 7:61-70.

${ }^{3}$ Pedersen J. The pregnant diabetic and her newborn. Copenhagen: Munksgaard, 1977.

4 White P. Pregnancy and diabetes. Medical aspects. Med Clin North Am $1965 ; 49: 1015-24$.

${ }^{5}$ Pedersen JF, Mølsted-Pedersen L. Early growth retardation in diabetic pregnancy. Br Med f 1979 ;i:18-9.

${ }^{6}$ Robinson HP. Sonar measurements of the fetal crown-rump length as a mean of assessing maturity in the first trimester of pregnancy. $\mathrm{Br} \mathrm{Med} \mathcal{F}$ 1973 ;iv :28-31.

${ }^{7}$ Eriksson U, Andersson A, Efendic S, Elde R, Hellerström C. Diabetes in pregnancy: effects on the fetal and newborn rat with particular regard to body weight, serum insulin concentration and pancreatic contents of insulin, glucagon and somatostatin. Acta Endocrinol 1980;94:354-64.

${ }^{8}$ White P. Diabetes mellitus in pregnancy. Clin Perinatol 1974;1:331-47.

${ }^{9}$ Mills JL, Baker L, Goldman AS. Malformations in infants of diabetic mothers occur before the seventh gestational week. Diabetes 1979;28: 292-3.

${ }^{10}$ Leslie RDG, Pike DA, John PN, White JM. Haemoglobin $A_{1}$ in diabetic pregnancy. Lancet 1978;ii:958-9.

${ }^{11}$ Pedersen J, Mølsted-Pedersen LM. Congenital malformations: the possible role of diabetes care outside pregnancy. Ciba Found Symp 1978; No $63: 265-71$.

(Accepted 12 May 1981)

W

\title{
Child-resistant containers: are we kidding ourselves?
}

\author{
A D GREIG, P D EWING, S B KENNY
}

\begin{abstract}
A 20-month-old child was accidentally poisoned after biting through the bottom of a medicine container and ingesting the tablets inside. Consequently a study was carried out to determine the force required to fracture 20 randomly selected 25 and $32 \mathrm{ml}$ polystyrene containers to see whether this exceeded the bite force of a child's jaw. Tests were performed at displacement rates of 0.5 and $10 \mathrm{~cm} / \mathrm{min}$. All the containers failed at well below the bite force recorded for children, which is $392 \mathrm{~N}$.

All containers must conform to a British Standards test that requires that they withstand a force of only $35 \mathrm{~N}$. Clearly this is not enough to safeguard small children. The use of polystyrene containers should be scrutinised closely, as the case of accidental poisoning reported may not be unique.
\end{abstract}

Wexham Park Hospital, Slough, Berkshire

A D GREIG, MB, BS, senior house officer in paediatrics

S B KENNY, BPHARM, MPS, staff pharmacist

Mechanical Engineering Department, Imperial College of Science and Technology, London SW7 $2 B X$

P D EWING, DIC, senior research officer

\section{Introduction}

We re-examined the effectiveness of child-resistant containers after an unusual case of accidental poisoning in a 20-month-old child and report here our results.

\section{Case report}

A child, aged 20 months, was admitted to the paediatric unit having taken an unknown quantity of red tablets. These were later identified as dothiepin (Prothiaden) $75 \mathrm{mg}$. According to the mother, the child had bitten through the bottom of a medicine container and gained access to the tablets (fig 1). Saliva had entered the container via the hole and had struck most of the tablets together. This had caused the colour to run and rendered them unidentifiable.

There were no abnormal findings on examination. The child was treated with ipecacuanha, observed for 48 hours, and discharged after showing no ill effects.

\section{Experimental method and results}

The container that the child had bitten had been made of polystyrene and was $32 \mathrm{ml}$ in size. We tested the force required to fracture $25 \mathrm{ml}$ and $32 \mathrm{ml}$ containers manufactured by the firm that had made the original container; these were selected because they are commonly used by hospital pharmacies and fit readily into a child's mouth.

Tests to fracture were performed, on 20 randomly selected containers of each size, by an Instron Universal testing machine. The 
object was to determine whether the force to fracture exceeded the bite force of a child's jaw. The container, with the top screwed on securely, was placed on a solid wooden base mounted on the fixed cross-head of the machine. It was loaded to fracture by using a double ball-ended striker attached to a load cell on the moving cross-head of the machine (fig 2). The position of the striker on the container simulated the

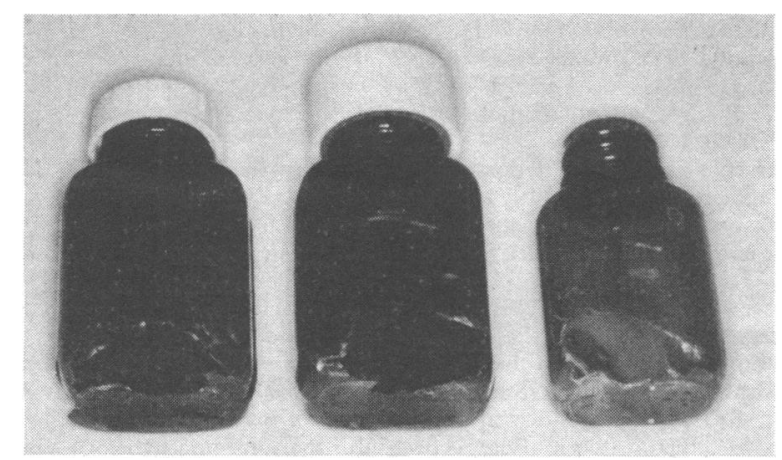

FIG 1 - Containers that failed after being bitten. The container on the left is the one mentioned in the case report: note that the top is still securely locked and is not child resistant.

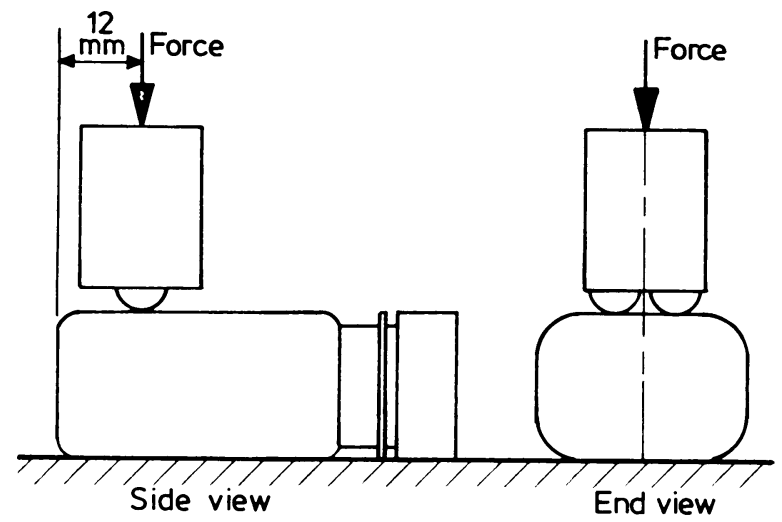

FIG 2-Position of striker.

average position of a child's teeth when the container is inserted into the mouth. Measurements taken from several children aged 2-5 years suggested that the front teeth would strike or bite the container at a distance of $12 \mathrm{~mm}$ from the bottom. Tests were performed at displacement rates of $0.5 \mathrm{~cm} / \mathrm{min}$ and $10 \mathrm{~cm} / \mathrm{min}$.

Table I shows the results of the tests on the containers. Tests 1-10 for both sizes of container were at a displacement rate of $0.5 \mathrm{~cm} / \mathrm{min}$ and tests $11-20$ at a rate of $10 \mathrm{~cm} / \mathrm{min}$. Table II shows the average fracture forces in the tests for the two sizes of container. The results show some rate dependence, the average fracture force being higher for a faster rate, as would be expected for crystal polystyrene. ${ }^{1}$ Table I shows that all the containers failed well below the bite force recorded for children of $392 \mathrm{~N}^{12}$ Even if this value was halved $95 \%$ of the containers would fail below it.

On inspection of the fractured containers the failure zones were similar to those in the containers that had failed after being bitten (fig 1).

\section{Discussion}

Child-resistant containers were produced in response to demands for greater protection of children against accidental poisoning. ${ }^{2-6}$ They take advantage of the greater strength of adults and generally incorporate a locking mechanism.

Children are liable to accidental poisoning even in the most carefully run homes. The unorthodox method reported here by which the child gained entry to the tablet container is a cause for concern. The child had evidently bitten through the container because teeth marks were clearly seen around the base. Small $\stackrel{\varrho}{c}$ but sharp fragments of the container might well have severely lacerated the child's mouth, tongue, and fingers.

Containers should be rigid enough to prevent damage to their contents $^{7}$ and should conform to British Standard 1679 part 4. ${ }^{8} \underset{\mathcal{D}}{\mathcal{D}}$ In this test a random sample of five containers should be able to withstand a force of $35 \mathrm{~N}$ on all sides. This test does not go far $?$ enough to safeguard small children, who may easily gain entry to containers by unconventional means.

TABLE I-Values of fracture force for 25 and $32 \mathrm{ml}$ containers (the bite force of children is $392 \mathrm{~N}$ )

\begin{tabular}{lccc}
\hline & & \multicolumn{2}{c}{ Fracture force $(\mathrm{N})$} \\
\cline { 3 - 4 } $\begin{array}{c}\text { Test } \\
\text { No }\end{array}$ & $\begin{array}{c}\text { Displacement rate } \\
(\mathrm{cm} / \mathrm{min})\end{array}$ & $25 \mathrm{ml}$ container & $32 \mathrm{ml}$ container \\
\hline 1 & 0.5 & $51 \cdot 8$ & 122.5 \\
2 & 0.5 & 92.2 & 107.9 \\
3 & 0.5 & 72.6 & 106.8 \\
4 & 0.5 & 81.3 & 106.4 \\
5 & 0.5 & 79.4 & 156.9 \\
6 & 0.5 & 40.2 & 102.9 \\
7 & 0.5 & 102.9 & 100.0 \\
8 & 0.5 & 136.3 & 101.0 \\
9 & 0.5 & 66.5 & 68.6 \\
10 & 0.5 & 101.0 & 109.8 \\
11 & 10.0 & 135.0 & 132.4 \\
12 & 10.0 & 65.7 & 191.2 \\
13 & 10.0 & 106.8 & 151.9 \\
14 & 10.0 & 93.1 & 196.1 \\
15 & 10.0 & 215.7 & 92.1 \\
16 & 10.0 & 185.3 & 187.3 \\
17 & 10.0 & 176.6 & 176.5 \\
18 & 10.0 & 75.5 & 116.7 \\
19 & 10.0 & 51.9 & 59.8 \\
20 & 10.0 & 124.5 & \\
& & & \\
\hline
\end{tabular}

TABLE II-Average fracture force for each container at displacement rates of 0.5 and $10.0 \mathrm{~cm} / \mathrm{min}$

\begin{tabular}{|c|c|c|c|}
\hline \multirow{2}{*}{$\begin{array}{l}\text { Test } \\
\text { No }\end{array}$} & \multirow{2}{*}{$\begin{array}{l}\text { Displacement rate } \\
(\mathrm{cm} / \mathrm{min})\end{array}$} & \multicolumn{2}{|c|}{$\begin{array}{l}\text { Average fracture } \\
\text { force }(N)\end{array}$} \\
\hline & & $25 \mathrm{ml}$ & $32 \mathrm{ml}$ \\
\hline $\begin{array}{r}1-10 \\
11-20\end{array}$ & $\begin{array}{r}0.5 \\
10 \cdot 0\end{array}$ & $\begin{array}{r}83 \cdot 2 \\
120 \cdot 0\end{array}$ & $\begin{array}{l}107 \cdot 8 \\
138 \cdot 4\end{array}$ \\
\hline
\end{tabular}

Gross inspection of the containers tested showed many flaws in the polystyrene mouldings. These usually occurred around the base. One container was so thin across the base that we were surprised that it had escaped quality control. It obviously did 5 not conform with BS 1679 part 4, but it is unlikely that it would N have been used by the pharmacy.

The forces to fracture (table I) show that a young child can easily bite through these containers. We doubt whether any of the containers tested would have failed the British Standards test, in which containers have to withstand a force without fracturing of only $35 \mathrm{~N}$ applied centrally on the largest plane surface for one minute. The lowest force to fracture in the tests reported here was $51.8 \mathrm{~N}$.

There are obvious difficulties in producing a child-resistant container, but attention has been directed on to the lid at the expense of the container itself, which has been overlooked. The use of polystyrene containers should be scrutinised closely, as accidental poisoning by the manner described may not be unique.

\section{References}

1 Marshall GP, Culver LE, Williams JG. Fracture phenomena in polystyrene. International Fournal of Fracture 1973;9:295-309. 
1a Carlsson GE. Bite force and chewing efficiency. In: Kawamura Y, ed. Frontiers of oral physiology. Vol 1. Basle: Karger, 1974:265-92.

2 Done AK. The design and testing of safety packaging. Drug and Cosmetic Industry $1971 ; 5: 41-4,154-6$.

${ }^{3}$ Elmer KR. Design of a child-resistant closure. Manufacturing Chemist $1973 ; 44: 28-9$.

4 Myers JA. Prevention of accidental poisoning by safety packaging. Pharm f $1971 ; 206: 564-5$.

5 Turk JG. The search for a safety closure. Drug and Cosmetic Industry $1967 ; 100: 38-41,167-71$.

\section{SHORT REPORTS}

\section{Chloramphenicol-resistant Salmonella typhimurium meningitis in an adult}

Salmonella typhimurium meningitis is virtually unknown in adults. ${ }^{1}$ We report such a case, complicated by chloramphenicol resistance of the organism and a preterminal cerebellar abscess.

\section{Case report}

A 65-year-old woman with maturity-onset diabetes and a history of cholecystectomy was admitted to the infection unit with a three-day history of diarrhoea and vomiting. She was feverish (39 C), had a headache, and was confused, dehydrated, and semiconscious with pronounced neckstiffness. There was nystagmus on horizontal and vertical gaze and mild left Horner's syndrome.

Lumbar puncture produced turbid cerebrospinal fluid with distinct polymorph pleocytosis $\left(4 \cdot 6 \cdot 10^{9} / 1\right.$ and a protein concentration of over $10 \mathrm{~g} / 1$. Cerebrospinal fluid glucose concentration was $18.8 \mathrm{mmol} / 1(339 \mathrm{mg} / 100 \mathrm{ml})$ and plasma glucose $33.8 \mathrm{mmol} / 1(609 \mathrm{mg} / 100 \mathrm{ml})$. No organisms were seen on microscopy, but bacterial meningitis was diagnosed clinically and antimicrobial treatment started with high-dosage intravenous bolus benzylpenicillin, gentamicin, and metronidazole to cover a range of possibilities.

Peripheral white cell count was $12 \cdot 3 \cdot 10^{9} / 1$ with $80^{\circ}$, neutrophils. Radiographs of the chest, abdomen, pelvis, skull, and cervical and lumbar spine were normal. Blood cultures were sterile but $S$ typhimurium, subsequently shown to be phage type $204 \mathrm{C}$, was isolated from cerebrospinal fluid and stools two days after admission. Treatment was then changed to chloramphenicol. On the fifth day after admission, however, the organism was shown to be resistant to chloramphenicol with a minimal inhibitory concentration of greater than $32 \mathrm{mg} / \mathrm{ml}$ when tested by the plate diffusion method. Chloramphenicol was therefore stopped and definitive treatment with ampicillin and mecillinam, to which the organism was sensitive, was begun. Until this time there had been little clinical improvement. Dexamethasone and mannitol were also given and the hyperglycaemia was controlled with actrapid.

She responded slowly with restoration of consciousness and decreasing cerebrospinal fluid pleocytosis, becoming rational and free from headache, but developed left facial pain, impaired sensation over the left trigeminal nerve dermatome, and a mild right hemiparesis. Radiographs of the internal auditory meati and a computed tomographic scan proved normal. Recurrent bronchopulmonary and urinary infections arose with intragastric feeding and her indwelling catheter, but she was eventually mobilised and became cheerful, lucid, and ambulant. The left facial pain and Horner's syndrome persisted, but the right hemiparesis resolved.

On the 80th hospital day she suddenly became comatose with neck stiffness and a dense right hemiplegia. Subarachnoid hacmorrhage from mycotic ancurysm was diagnosed clinically and apparently substantiated by bloodstained cerebrospinal fluid and xanthochromia. Despite recovery after treatment with tranexamic acid, ampicillin, and dexamethasone she relapsed 10 days later and died.

Necropsy disclosed residual basal meningitis and a left cerebellar abscess $4 \mathrm{~cm}$ in diameter from which $S$ typhimurium was cultured.

\section{Comment}

This patient was admitted with diarrhoea and meningitis due to $S$ typhimurium. The infection had been acquired by drinking unpasteurised milk from a herd infected with this strain. Seventeen other people also developed salmonellosis from this source.

$S$ typhimurium is usually associated with self-limiting "gastroenteritis." Septicaemia is uncommon and meningitis exceptional, save in the premature infant." This patient's age, diabetes, and previous cholecystectomy possibly had a role in her severe illness. Other factors associated with a poor prognosis in bacterial meningitis include raised
6 Wood R. The quest for a really child-safe closure system. Manufacturing Chemist $1973 ; \mathbf{4 4}: 22-5$.

7 Carter SJ, reviser. Containers and closures. Cooper and Gunn's dispensing

${ }^{8}$ British Standards Institute. Test for mechanical strength. BS 1679 part 4. Appendix C.

(Accepted 29 May 1981) for pharmaceutical students. 12th ed. London: Pitman, 1979:13.

cerebrospinal fluid protein concentration and delay in starting correct treatment, ${ }^{3}$ both of which applied here. Correct treatment with high doses of ampicillin (intravenous and intrathecal) and mecillinam (intravenous) was not started until six days after her admission. Mecillinam has not to our knowledge been used in salmonella meningitis previously, though its use in salmonella endocarditis has been described. ${ }^{4}$

Despite a total of $300 \mathrm{~g}$ ampicillin and $50 \mathrm{~g}$ mecillinam our patient died with residual basal meningitis and an intracranial abscess, both recognised but rare complications of salmonellosis. ${ }^{15}$ Their occurrence in this case highlights the problem in diagnosing salmonella meningitis and in eradicating the organism from the central nervous system.

Requests for reprints should be sent to Dr M Ellis.

${ }^{1}$ Kauffman CA, St Hilaire RJ. Salmonella meningitis. Occurrence in an adult. Arch Neurol 1979;36:578-80.

${ }^{2}$ Black PH, Kunz LJ, Swartz MN. Salmonellosis-a review of some unusual aspects. $N$ Engl $\mathcal{F}$ Med 1960;262:811, 864, 921.

${ }^{3}$ Carpenter RC, Petersdorf RG. The clinical spectrum of bacterial meningitis. Am J Med 1962;33:262-75.

+ Shanson DC, Brigden W, Weaver EJM. Salmonella enteritidis endocarditis. Br Med F 1977;i:612-3.

${ }^{5}$ Saphra I, Winter JW. Clinical manifestations of salmonellosis in man. N Engl f Med 1957;256:1128-34.

(Accepted 24 March 1981)

The City Hospital, Aberdeen AB2 4NJ

M E ELLIS, MRCP, registrar (now senior registrar, infection unit, Monsall Hospital, Manchester)

C C SMITH, FRCP, consultant physician

T M S REID, MRCPATH, consultant microbiologist

I A PORTER, FRCPATH, consultant microbiologist

\section{Vitamin D deficiency and deafness}

In metabolic and connective tissue disorders that cause secondary skeletal abnormalities temporal bone disease and deafness may be included in the clinical picture. These disorders include osteitis deformans, osteogenesis imperfecta, osteitis fibrosa cystica, osteoporosis, and osteopetrosis. ${ }^{1}$ We report on two patients in whom vitamin $\mathrm{D}$ deficiency resulted in biochemical osteomalacia and was associated with bilateral cochlear deafness.

\section{Case reports}

CASE 1

A 35-year-old Asian man, who had been a vegan for four years, was referred to the ear, nose, and throat department with a two-year history of progressive bilateral deafness and tinnitus. Before outpatient consultation a severe headache had necessitated emergency medical admission for investigation. There was no vertigo or family history of deafness. The only physical sign was localised tenderness over the left frontotemporal region. The tympanic membranes were normal.

Audiological assessment showed bilateral subtotal trough-shaped fully recruiting cochlear deafness, with a mean pure-tone threshold of $85 \mathrm{db}$. Bithermal caloric tests were normal. Tomography showed bilateral cochlear demineralisation. Preliminary biochemical evaluation (table) indicated a 